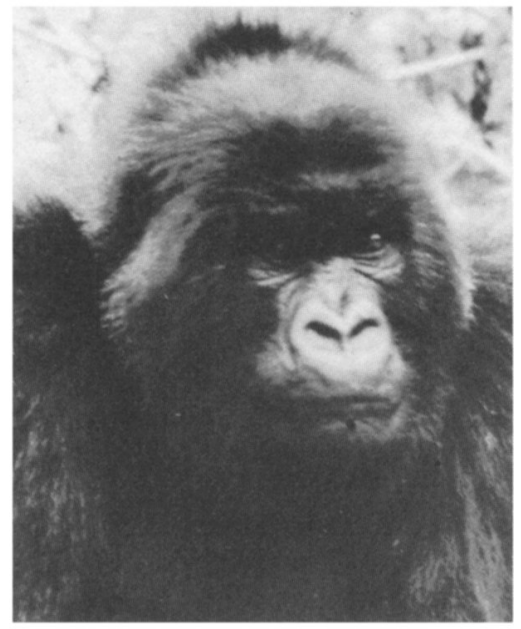

\title{
The Mountain Gorilla Project: Progress Report 3
}

\author{
A.H. Harcourt
}

Dr Harcourt, Project Coordinator of the Mountain Gorilla Fund, initiated by FPS and the People's Trust for Endangered Species, describes the remarkable success of this vital project.

The Mountain Gorilla Project started with four main programmes for the conservation of the gorilla in Rwanda's Parc National des Volcans: the Training and Equipping of a Park Guard Force (AWLF/PTES responsibility); Conservation Education (FPS/PTES); Tourism Development (FPS/PTES); and a Building Programme of offices and housing for the park guards (AWLF/WWF). Thanks largely to Bill Weber and Amy Vedder of the University of Wisconsin, two of these, the Conservation Education and Tourism Development Programmes, have been as successful as we could ever have hoped. Progress on the others has been distressingly slow due to probably almost inevitable bureaucratic delays. Nevertheless, the training and equipping programme is now under way, and only the building project remains to be started.

Although none of the projects is more important than any other - all are vital if the mountain gorilla is to be saved - the one with the most far-reaching effects in the long term is probably conservation education. The specially equipped van so necessary to this project (shown in the last issue of Oryx) arrived in Rwanda in early May, having been held up by a dock strike. Funded by FPS/PTES and outfitted by the WWF Education Project team in Gloucestershire, this is now being used to show films and slide presentations on the conservation and ecology of Rwanda's wildlife, especially the gorilla, in schools and villages throughout the country. In addition, Weber and Vedder have contributed sections on ecology and conservation to Rwanda's school curriculum and, most importantly, have prepared for distribution to every secondary school pupil a booklet, Rwandan Heritage, that describes with simple colour pictures the principles of conserving water, land and wildlife.

This whole conservation education programme is so important that FPS/PTES have undertaken to fund it for another year, and Conrad and 
Rosalind Aveling, who have already co-directed a three-year conservation education programme in Indonesia, will be taking over from Weber and Vedder in August. After that, the Belgian Technical Assistance Programme will assume responsibility for it and, with continuity supplied by a Rwandan who has worked with Weber and Vedder and will have worked with the Avelings, the programme should be assured for many years to come.

\section{Sightings Guaranteed}

The tourism development programme has up to now been described as the Gorilla Habituation Project. However, it involves far more than simply habituating a group of gorillas to tourists. Weber and Vedder have also trained guides in European languages and the ecology of the park so that they can teach tourists how to behave in the park, and answer simple questions about the gorillas. Furthermore, with the help of Jean Pierre von der Becke, the MGP's Project Manager in Rwanda, they have organised a booking system to control tourist visits to the gorillas so that, while allowing a reasonable number of tourists excellent views of the gorillas, the gorillas themselves are disturbed as little as possible. The programme has been so successful that, with the guarantee that every tourist who sets out to the gorillas can see them, visitors have increased by more than 100 per cent over last year, and the increased fees have provided vitally needed extra revenue for the park. The Parc des Volcans is one of only a handful of African parks where the visitor goes on foot. With the added excitement of views of totally wild gorillas at distances sometimes of less than five yards, even widely travelled tourists now describe their visit as one of their most memorable experiences.

Along with these two main programmes, FPS, PTES and WWF are also supporting a general public awareness programme, essentially a propaganda campaign that involves the projection of posters, booklets, calendars etc., to disseminate the conservation message.

The equipment required by the 40 men of the Park Guard Force has at last arrived in Rwanda; the hold-up has been that tax exemption on equipment was not received until early this year, and we wanted to ensure that all donors' contributions went directly to conservation work, rather than on import taxes. Tradewinds Airways Ltd very generously delivered the boots, sweaters, ponchos, rucksacks, sleeping bags, and tents; they arrived in May, and now von der Becke can start the Guard Training Programme in earnest.

Lastly the building programme awaits organisation for WWF's earmarked funds to be used immediately.

Finally we want to thank all the donors whose contributions have made possible the success story of the MGP so far. Obviously, nothing could have been accomplished without them. And money is still coming in. The largest single donation so far received was $£ 2500$ from the Readers’ Digest to celebrate the publication of their enlarged version of David Attenborough's Life on Earth in May 1980. It was the author's suggestion the money go to the MGP.

With generosity such as this we shall be able to extend the Mountain Gorilla Project to the whole Virunga conservation area, and ensure the survival of the mountain gorilla.

\section{If you would like to support the Mountain Gorilla Project please send your gift c/o FFPS, The Zoo, Regent's Park, London NW1 4RY.}

